\title{
Del(10q23)/PTEN Gene Locus Deletion Analysis Method
}

National Cancer Institute

\section{Source}

National Cancer Institute. del(10q23)/PTEN Gene Locus Deletion Analysis Method. NCI

Thesaurus. Code C158869.

A request to enter the specific molecular analysis method used to detect and identify deletion of the PTEN gene located in the vicinity of $10 q 23$. 